\title{
Serial assessment of endothelial function 1,6, and 12 months after ST-elevation myocardial infarction
}

\author{
Jasveen J. Kandhai-Ragunath ${ }^{1}$. Carine J. M. Doggen ${ }^{2}$ Liefke C. van der Heijden ${ }^{1}$ Marlies M. Kok ${ }^{1}$ Paolo Zocca ${ }^{1}$. \\ Bjorn de Wagenaar ${ }^{2} \cdot$ Cees Doelman ${ }^{3} \cdot$ Harald T. Jørstad $^{4} \cdot$ Ron J. G. Peters ${ }^{4} \cdot$ Clemens von Birgelen $^{1,2}$
}

Received: 22 September 2017 / Accepted: 2 March 2018 / Published online: 14 March 2018

(c) The Author(s) 2018

\begin{abstract}
Knowledge about the changes in endothelial function after ST-elevation myocardial infarction (STEMI) is of substantial interest, but serial data are scarce. The aim of the present study was to noninvasively evaluate whether endothelial function, as assessed shortly after primary percutaneous coronary intervention (PPCI) for STEMI, may improve until 12-month follow-up. This prospective observational cohort study was performed in patients in the RESPONSE randomized trial who participated in a substudy and underwent noninvasive assessment of endothelial function at 1 (baseline), 6, and 12-month follow-up after treatment of a STEMI by PPCI. The reactive hyperemia peripheral artery tonometry (RH-PAT) method was used to assess endothelial function (higher RH-PAT index signifies better function). Of the 70 study participants, who were $57.4 \pm 9.7$ years of age, $55(78.6 \%)$ were male and $9(13 \%)$ had diabetes. The endothelial function deteriorated significantly during follow-up: the RH-PAT index at baseline, 6 , and 12-month follow-up was $1.90 \pm 0.58,1.81 \pm 0.57$, and 1.69 \pm 0.49 , respectively $(p=0.04)$. Although patients were carefully treated in outpatient clinics and adequate pharmacological therapy was prescribed, we noted an increase in total cholesterol $(p=0.001)$, LDL cholesterol $(p=0.002), \mathrm{HbA1C}(p=0.054)$, and diastolic blood pressure $(p=0.047)$ However, multivariate analysis revealed that this increase in cardiovascular risk factors could not explain the observed deterioration in endothelial function. In patients with STEMI, we observed a significant deterioration in endothelial function during 12 months after PPCI that could not be explained by changes in the traditional cardiovascular risk profile.
\end{abstract}

Keywords Endothelial function - Reactive hyperemia peripheral artery tonometry $\cdot$ ST-segment elevation myocardial infarction (STEMI) · Primary PCI · Coronary artery disease

\section{Introduction}

Coronary heart disease remains the leading cause of morbidity and mortality in societies with a Western lifestyle [1]. Patients who experienced an ST-segment elevation

Clemens von Birgelen

c.vonbirgelen@mst.nl

1 Department of Cardiology, Thoraxcentrum Twente, MST, Koningsplein 1, 7512KZ Enschede, The Netherlands

2 Department Health Technology and Services Research, MIRA, Institute for Biomedical Technology and Technical Medicine, University of Twente, Enschede, The Netherlands

3 Medlon Laboratory Diagnostics, Medisch Spectrum Twente, Enschede, The Netherlands

4 Department of Cardiology, Academisch Medisch Centrum, Amsterdam, The Netherlands myocardial infarction (STEMI) and were treated by primary percutaneous coronary intervention (PPCI) still bear a substantially increased risk of another cardiovascular event, despite all efforts to adequately treat them and to modify their cardiovascular risk factors [2]. Endothelial dysfunction, which develops in conduction and resistance vessels of patients with atherosclerosis, has been associated with an increased cardiovascular risk [3-5]. In patients with a recent STEMI, the assessment of endothelial function and its changes over time might help identify patients who require a further optimization of risk factors or an individualized therapy. Nevertheless, so far, data of changes in endothelial function in patients with a recent STEMI are extremely rare. An important first step could be to obtain such serial data in a population of STEMI patients and to evaluate the relation between changes in endothelial function and traditional cardiovascular risk factors. 
Several techniques are available for a noninvasive assessment of peripheral endothelial function, which has been shown to correlate well with coronary endothelial function [6, 7]. While the ultrasound-based assessment of flowmediated dilatation of the brachial artery requires significant training and experience, reactive hyperemia peripheral artery tonometry (RH-PAT) is an operator-independent method that has proved its value in comparison with an ultrasound-based approach and with acetylcholine-based assessment of coronary endothelial function [8,9]. An RHPAT index of peripheral endothelial function was shown to be reduced in the presence of proven dysfunction of the coronary endothelium [9].

In the present prospective substudy of the RESPONSE (Randomised Evaluation of Secondary Prevention by Outpatient Nurse SpEcialists) trial [10], we obtained serial data on endothelial function and evaluated the hypothesis that, following a STEMI, endothelial dysfunction may improve under medical therapy (e.g., with statins or angiotensin converting enzyme inhibitors) and standard measures of secondary prevention [11]. For that purpose, we used the RHPAT approach in patients with a recent STEMI and assessed endothelial function at 1-, 6- and 12-month follow-up after PPCI.

\section{Methods}

\section{Study population and design}

This prospective cohort study was performed in 70 STEMI patients in the RESPONSE trial [10], who underwent treatment by PPCI for acute STEMI ( $\leq 12 \mathrm{~h}$ after symptom onset) and noninvasive assessment of endothelial function with the RH-PAT method at 1-, 6- and 12-month follow-up. PPCIs were performed at Thoraxcentrum Twente, the Netherlands. Of a total of 75 STEMI patients in the RESPONSE trial with RH-PAT measurements, 70 had analyzable serial RH-PAT registrations.

Patients were eligible for enrollment if they: were between 18 and 80 years of age; were available for and willing to adhere to the follow-up procedures; had no surgery or additional PCI planned within 8 weeks from PPI; and had a life expectancy of at least 2 years in the absence of heart failure NYHA class III or IV. Details of the randomized RESPONSE trial have previously been reported [10].

As inflammation and repair processes of the infarcted myocardium might have disturbed endothelial function measurements during the first weeks after the STEMI and endothelial dysfunction has not been fully recovered under medication, endothelial function was first assessed during 1-month follow-up (i.e., 4-6 weeks after PPCI) [12-14]. All patients were seen in the outpatient clinic, where noninvasive assessment of the endothelial function was performed according to strict rules in a dedicated laboratory [15]. All patients provided written informed consent for participation in the substudy. The study complied with the Declaration of Helsinki for investigation in human beings and was approved by the Medical Ethical Committee Twente in Enschede, the Netherlands.

\section{Coronary intervention and concomitant medical therapy}

Patients were treated in the ambulance with an intravenous bolus of 5.000 IE of unfractionated heparin, a loading dose of $\geq 300 \mathrm{mg}$ of acetylsalicylic acid (orally or intravenously) and an oral loading dose of $600 \mathrm{mg}$ of clopidogrel. In 50 patients, a weight-adjusted intracoronary bolus of abciximab was administered after visualizing the culprit coronary artery. PPCI procedures were generally performed via the femoral route through $6 \mathrm{~F}$ sheaths. Pharmacological therapy, use of aspiration catheters, lesion preparation (vs. direct stenting), and stent postdilatation were performed according to current guidelines and the operator's judgment and discretion. Following primary PCI, a heart team carefully assessed the coronary angiographies and, if required, patients underwent a staged PCI for additional coronary lesions, which was generally performed within 1-2 weeks from primary PCI.

\section{Noninvasive assessment of endothelial function with the RH-PAT method}

Endothelial function was evaluated with the RH-PAT method. The finger pulse wave amplitude was assessed with the EndoPAT-2000 sensing device and finger plethysmographic probes (Itamar Medical, Caesarea, Israel), both at baseline and during ischemia-induced hyperemia. All measurements were performed in the early morning in a dedicated laboratory after patients had fasted for at least $8 \mathrm{~h}$. Patients also had to refrain from caffeine consumption, smoking, and vasoactive medications. At least $15 \mathrm{~min}$ prior to testing, blood pressure was measured and a blood sample was drawn in the control arm. Before any measurement, patients had an acclimatization period of $20 \mathrm{~min}$ in a quiet room, lying in a hospital bed at an ambient temperature of $21-23{ }^{\circ} \mathrm{C}$.

The RH-PAT method has previously been reported in detail $[15,16]$. In brief, measurements were performed using probes on the index fingers of both the study and control arms. Baseline measurements were recorded for $5 \mathrm{~min}$ prior to inducing ischemia by inflating a blood pressure cuff on the upper arm of the study arm for $5 \mathrm{~min}$ to suprasystolic pressures. After the transient arterial occlusion, the increase in blood flow in the finger of the study arm was assessed, serving as an index of the endothelium-dependent vasodilator function. The ratio of the pulse amplitude of the 
hyperemic finger and the baseline amplitude was calculated. Subsequently, that ratio was divided by the corresponding ratio, obtained in the control arm, to calculate the RH-PAT index (high values indicate good endothelial function). The maximum hyperemic response can be expected 90-120 s after cuff deflation [17]. Therefore, in the present study, the reactive RH-PAT index was calculated as the ratio of the mean hyperemic pulsed wave analysis over a period of $30 \mathrm{~s}$, beginning at $90 \mathrm{~s}$ after cuff deflation, divided by the baseline pulsed wave analysis (mean baseline measurements for $3.5 \mathrm{~min}$ ), and normalized to the concurrent measurements of the control arm [17].

\section{Characteristics of the subjects and the definitions used}

The following information was documented at baseline: RH-PAT; age; sex; body mass index (BMI, $\left.\mathrm{kg} / \mathrm{m}^{2}\right)$; arterial hypertension (blood pressure of $>140 / 90 \mathrm{mmHg}$ or treatment with anti-hypertensive medication); history of smoking (previous or current smoker); history of previous myocardial infarction and/or coronary revascularization by means of PCI or bypass surgery; the presence of diabetes mellitus (patient history and/or treatment with insulin or oral antiglycemic agents); and history of hypercholesterolemia or treatment with lipid-lowering drugs. Procedure details were also documented. At follow-up, RH-PAT and systolic blood pressure, diastolic blood pressure, and BMI were measured; current smoking habit and medication use were documented. Blood samples were analyzed for the measurements of total cholesterol, HDL cholesterol, LDL cholesterol, triglycerides, fasting glucose, and $\mathrm{HbAlc}$. Patients were instructed to fast for a period of $8 \mathrm{~h}$ prior to drawing of the blood sample. At the three times of follow-up, we assessed the proportion of patients on adequate cardiovascular risk factor control, according to the 2003 European guidelines of cardiovascular disease prevention [11].

\section{Statistical analyses}

Data are presented as frequencies (\%) or mean \pm standard deviation (SD). Between-group comparisons of RH-PAT were conducted using longitudinal mixed models. Time was treated as a categorical variable (baseline, 6, and 12 months). Compound symmetry covariance structure was used for time. Only those variables that significantly modified over time were included in the subsequent multivariate analyses. As repeated covariates, we included $\mathrm{Hb} 1 \mathrm{Ac}$, diastolic blood pressure, total cholesterol, and LDL cholesterol. A $p$ value $<0.05$ was considered statistically significant. All analyses were conducted using SPSS version 23.0 (SPSS Inc., Chicago, IL, USA).

\section{Results}

\section{Characteristics of study population and treatment}

Patient characteristics at baseline are displayed in Table 1. The study population had a mean age of $57.4 \pm 9.7$ years, and most patients were men $(78.6 \%)$. Patients had a BMI of $28.0 \pm 4.0 \mathrm{~kg} / \mathrm{m}^{2}$ at inclusion; $40.0 \%$ were smokers while $12.9 \%$ had diabetes, $28.6 \%$ hypertension, and $24.3 \%$ hypercholesterolemia. Eight patients $(11.4 \%)$ had a history of previous PCI. The index PPCI procedure was performed through the femoral route in $98.4 \%$ of the patients with an ischemia time of $155.9 \pm 105.5 \mathrm{~min}$. Of all patients, $73.9 \%$ had single-vessel disease and $89.9 \%$ had a left ventricular ejection fraction $>50 \%$ prior to discharge (Table 1). At discharge after PPCI, European guidelinesuggested medication was prescribed as follows: $95.5 \%$ of all patients were prescribed acetylsalicylacid, $95.7 \%$ clopidogrel, $85.1 \%$ beta-blockers, $49.3 \%$ angiotensin converting enzyme inhibitors, $13.4 \%$ angiotensin receptor blockers, and $94.0 \%$ statins (Table 2).

\section{Endothelial function in serial measurements}

The endothelial function decreased over time, starting at a mean RH-PAT index of $1.90 \pm 0.58$ at baseline, to $1.81 \pm 0.57$ at 6 -month follow-up, and eventually to $1.69 \pm 0.49$ at 12 -month follow-up $(p=0.04$ in mixed model). Further details of the RH-PAT index measurements are displayed in Table 1.

\section{Relation between changes in risk factors and endothelial function}

Table 3 indicates, for several variables, the proportion of patients who were not on adequate risk factor control, according to the 2003 European guidelines of cardiovascular disease prevention. Despite comprehensive medical treatment, the number of patients did not change over time. From 6 to 12 months, there was only a significant decrease in the use of clopidogrel $(p<0.01)$.

A longitudinal mixed model analysis shows that, of all cardiovascular risk factors assessed, the following worsened significantly over time: HbA1c; diastolic blood pressure; total cholesterol; and LDL cholesterol (Table 4). However, multivariate analysis demonstrated that none of the cardiovascular risk factors was found to be responsible for the decrease in endothelial function over time. Results of the multivariate analysis are displayed in Table 4. 
Table 1 Characteristics of the study population

\begin{tabular}{|c|c|}
\hline Patients & $70(100)$ \\
\hline Male sex & $55(78.6)$ \\
\hline Age (years, mean $\pm S D$, min-max) & $57.4 \pm 9.7,38.3-78.8$ \\
\hline Body mass index $\left(\mathrm{kg} / \mathrm{m}^{2}, \text { mean } \pm \mathrm{SD}, \min -\mathrm{max}\right)^{\mathrm{b}}$ & $28.0 \pm 4.0,21.0-42.4$ \\
\hline Current smoker & $28(40.0)$ \\
\hline Diabetes mellitus & $9(12.9)$ \\
\hline Hypertension & $20(28.6)$ \\
\hline Hypercholesterolemia & $17(24.3)$ \\
\hline History of percutaneous coronary intervention & $8(11.4)$ \\
\hline History of coronary artery bypass grafting & $1(1.4)$ \\
\hline \multicolumn{2}{|l|}{ Maximum level of serum creatinine kinase ${ }^{a}$} \\
\hline$<500 \mathrm{U} / 1$ & $24(34.3)$ \\
\hline $500-1,000 \mathrm{U} / 1$ & $14(20.0)$ \\
\hline $1,000-2,000 \mathrm{U} / 1$ & $13(18.6)$ \\
\hline$>2,000 \mathrm{U} / 1$ & $17(24.3)$ \\
\hline \multicolumn{2}{|l|}{ Left ventricular ejection fraction ${ }^{a}$} \\
\hline$>50 \%$ & $62(89.9)$ \\
\hline $40-50 \%$ & $7(10.1)$ \\
\hline$<40 \%$ & $0(0)$ \\
\hline \multicolumn{2}{|l|}{ NYHA class ${ }^{\mathrm{a}}$} \\
\hline I & $66(95.7)$ \\
\hline II & $3(4.3)$ \\
\hline III & 0 \\
\hline IV & 0 \\
\hline Vascular access via femoral route ${ }^{c}$ & $63(98.4)$ \\
\hline Ischemia time (minutes, mean $\pm \mathrm{SD}, \min -\max )^{\mathrm{c}}$ & $155.9 \pm 105.5,20-600$ \\
\hline Systolic blood pressure $(\mathrm{mmHg}, \text { mean } \pm \mathrm{SD}, \min -\max )^{c}$ & $124.6 \pm 24.5,60-170$ \\
\hline Diastolic blood pressure $(\mathrm{mmHg}, \text { mean } \pm \mathrm{SD}, \min -\max )^{\mathrm{c}}$ & $76.6 \pm 14.7,35-110$ \\
\hline Heart rate during (beats/min, mean $\pm S D, \min -\max )^{c}$ & $73.8 \pm 18.0,46-115$ \\
\hline \multicolumn{2}{|l|}{ Extent of coronary artery disease ${ }^{a}$} \\
\hline 1 Vessel disease & $51(73.9)$ \\
\hline 2 Vessel disease & $15(21.7)$ \\
\hline 3 Vessel disease & $3(4.3)$ \\
\hline \multicolumn{2}{|l|}{ Type of stents implanted ${ }^{\mathrm{c}}$} \\
\hline Bare metal stents & $42(67.7)$ \\
\hline Drug-eluting stents & $18(29.0)$ \\
\hline Bare metal and drug-eluting stents & $2(3.2)$ \\
\hline Total stent length $(\mathrm{mm}, \text { mean } \pm \mathrm{SD}, \min -\mathrm{max})^{\mathrm{c}}$ & $34.4 \pm 23.9,13-132$ \\
\hline
\end{tabular}

Data are number (\%) unless otherwise stated. Baseline characteristics are reported NYHA New York Heart Association class of heart failure, STEMI ST-segment elevation myocardial infarction

${ }^{\mathrm{a}} 1$ missing

b2 missings

${ }^{c} 4-10$ missings

\section{Discussion}

\section{Main findings}

Following STEMI treated by PPCI, endothelial functionas measured by RH-PAT-did not improve from baseline at 1-12-month follow-up, despite the prescription of guideline-recommended medical therapy [11] in the majority of patients and counseling for cardiovascular risk factor reduction. In the present study population, endothelial function even decreased over time. Further statistical analyses found no relation between this deterioration in endothelial function and changes in traditional cardiovascular risk factors, of which some also showed deterioration over time. The 
Table 2 Serial data of endothelial function, variable patient characteristics, and medication prescribed

\begin{tabular}{lllll}
\hline Variables & Baseline & 6 months & 12 months & $P$ value \\
\hline Endothelial function RH-PAT index, mean \pm SD & $1.90 \pm 0.58$ & $1.81 \pm 0.57$ & $1.69 \pm 0.49$ & $0.04^{*}$ \\
Variable patient characteristics & & & & \\
Body mass index $>25 \mathrm{~kg} / \mathrm{m}^{2}$ & $52(76.5)$ & $52(80.0)$ & $53(79.1)$ & 0.71 \\
Current smoker & $29(41.4)$ & $23(33.8)$ & $25(36.8)$ & 0.92 \\
Systolic blood pressure $>140 \mathrm{mmHg}$ & $15(21.7)$ & $23(33.8)$ & $20(29.0)$ & 0.34 \\
Diastolic blood pressure $>90 \mathrm{mmHg}$ & $15(21.7)$ & $13(19.1)$ & $19(27.5)$ & 0.48 \\
Total cholesterol $>4.5 \mathrm{mmol} / 1$ & $7(10.0)$ & $8(11.4)$ & $8(11.6)$ & 0.76 \\
LDL cholesterol $>2.5 \mathrm{mmol} / 1$ & $10(14.3)$ & $8(11.4)$ & $8(11.6)$ & 0.63 \\
HDL cholesterol $<1.0 \mathrm{mmol} / 1$ & $32(45.7)$ & $29(41.4)$ & $25(36.2)$ & 0.26 \\
Triglycerides $>2.0 \mathrm{mmol} / 1$ & $5(7.1)$ & $6(8.6)$ & $10(14.5)$ & 0.15 \\
Medication prescribed & & & & \\
Acetylsalicylic acid & $64(95.5)$ & $63(94.0)$ & $63(94.0)$ & 0.70 \\
Clopidogrel & $67(95.7)$ & $62(93.9)$ & $39(57.4)$ & $<0.001$ \\
Oral anticoagulant & $3(4.5)$ & $2(3.0)$ & $2(3.0)$ & 0.64 \\
Beta blocker & $57(85.1)$ & $48(71.6)$ & $48(71.6)$ & 0.07 \\
ACE inhibitor & $33(49.3)$ & $36(57.1)$ & $34(50.7)$ & 0.86 \\
ARB & $9(13.4)$ & $12(18.8)$ & $9(13.4)$ & 1.00 \\
Calcium antagonist & $10(14.5)$ & $13(19.7)$ & $9(13.2)$ & 0.84 \\
Statin & $63(94.0)$ & $63(98.4)$ & $63(94.0)$ & 1.00 \\
\hline
\end{tabular}

Data are number (\%) unless otherwise stated. Baseline assessment was performed 4-6 weeks after the acute ST-elevation myocardial infarction

$A C E$ angiotensin converting enzyme, $A R B$ angiotensin receptor blocker, $H D L$ high density lipoprotein, $L D L$ low density lipoprotein

* $P$ value obtained from longitudinal mixed model analysis

Table 3 Differences in endothelial function and risk factors over time compared to baseline values

\begin{tabular}{|c|c|c|c|c|}
\hline Variables & Baseline & $\Delta$ at 6 months & $\Delta$ at 12 months & $P$ value* \\
\hline Endothelial function RH-PAT index & $1.90(1.77 ; 2.03)$ & $-0.09(-0.25 ; 0.07)$ & $-0.21(-0.36 ;-0.04)$ & 0.04 \\
\hline Body mass index $\left(\mathrm{kg} / \mathrm{m}^{2}\right)$ & $28.0(27.1 ; 29.0)$ & $0.12(-0.33 ; 0.58)$ & $0.16(-0.34 ; 0.67)$ & 0.76 \\
\hline $\mathrm{HbA} 1 \mathrm{c}(\mathrm{mmol} / \mathrm{l})$ & $6.01(5.80 ; 6.21)$ & $0.02(-0.07 ; 0.11)$ & $0.13(0.00 ; 0.26)$ & 0.054 \\
\hline Systolic BP (mmHg) & $131.2(127.5 ; 135.0)$ & $2.1(-2.6 ; 6.7)$ & $1.9(-2.8 ; 6.5)$ & 0.54 \\
\hline Diastolic BP (mmHg) & $79.6(76.9 ; 82.4)$ & $2.3(-1.0 ; 5.7)$ & $3.7(0.3 ; 7.1)$ & 0.047 \\
\hline Total Cholesterol (mmol/l) & $3.41(3.22 ; 3.59)$ & $0.31(0.11 ; 0.52)$ & $0.27(0.11 ; 0.44)$ & $<0.001$ \\
\hline LDL Cholesterol (mmol/l) & $1.71(1.57 ; 1.85)$ & $0.25(0.08 ; 0.42)$ & $0.17(0.04 ; 0.30)$ & 0.002 \\
\hline HDL Cholesterol (mmol/l) & $1.06(1.01 ; 1.13)$ & $0.03(-0.02 ; 0.07)$ & $0.02(-0.03 ; 0.07)$ & 0.45 \\
\hline Triglycerides $(\mathrm{mmol} / \mathrm{l})$ & $1.39(0.21 ; 1.56)$ & $0.07(-0.12 ; 0.27)$ & $0.17(-0.05 ; 0.40)$ & 0.19 \\
\hline
\end{tabular}

Data are mean (95\% confidence interval)

$\Delta$ difference from baseline, $B P$ blood pressure, $H b A l c$ glycated hemoglobin, $H D L$ high density lipoprotein, $L D L$ low density lipoprotein

$* P$ values obtained from longitudinal mixed model analysis

findings of the present study are unique, as it is the first to report long-term serial endothelial function measurements in STEMI patients during a period of 12 months after PPCI.

\section{Approaches to serially assess endothelial function}

Through the years, several methods have been developed to identify subjects with disturbed endothelial function, as they are at an increased risk of cerebrovascular [18] and cardiovascular events $[19,20]$. Coronary angiographic assessment after intracoronary injection of acetylcholine remains the "gold standard". The main limitations of this catheter-based approach are its invasiveness and inherent risk of complications. Moreover, it is not readily accessible in daily clinical practice. However, peripheral endothelial function correlates well with coronary endothelial function, reflecting 
Table 4 Prognostic factors of changes in endothelial dysfunction

\begin{tabular}{lcc}
\hline Variables & Est (SE) & $P$ value \\
\hline Intercept & $1.85(0.46)$ & \\
Time baseline (reference) & & \\
Time 6 months & $-0.09(0.09)$ & 0.28 \\
Time 12 months & $-0.14(0.10)$ & 0.14 \\
HbA1c & $-0.018(0.052)$ & 0.73 \\
Diastolic blood pressure & $-0.002(0.004)$ & 0.64 \\
Total cholesterol & $0.114(0.107)$ & 0.29 \\
LDL cholesterol & $-0.054(0.133)$ & 0.68 \\
Clopidogrel & $-0.15(0.12)$ & 0.21 \\
\hline
\end{tabular}

Est (SE) estimated (standard error), HbAlc glycated hemoglobin, $L D L$ low density lipoprotein

the systemic nature of atherosclerosis [6, 21]. Therefore, noninvasive methods were developed to assess endothelial health, all of which apply the principle of reactive hyperemia in response to ischemia in one of the upper extremities. The reactive hyperemia response of the brachial artery can be measured using high-frequency ultrasound, an approach that has proven to be accurate and reproducible in experienced hands [22]. This has previously been shown to predict the likelihood of coronary disease in patients with chest pain and estimate the long-term risk of cardiovascular events [19, 23].

Another method of measuring the reactive hyperemic response to ischemia is RH-PAT. Data obtained with RHPAT were shown to correlate well with both findings of the high-frequency ultrasound method and coronary endothelial function $[9,10,20]$. After the identification of patients with endothelial dysfunction, who are known to be at an increased risk of developing cardiovascular events [4], aggressive modification of traditional cardiovascular risk factors might improve patient outcome [24, 25]. Such improvement in outcome has been attributed to functional improvement of the endothelium, while reversal of atherosclerosis-related structural changes to the vessel wall is more difficult to achieve and may, to a much lesser extent, account for an improvement in clinical prognosis [26].

\section{Previous studies with serial endothelial function measurement}

Other research groups have performed serial endothelial function measurements in different study populations, assessing changes during a period of 3-6 months. Kitta et al. [27] previously examined 251 patients with newly diagnosed stable coronary disease and reduced flow-mediated dilatation of the brachial artery, showing that, in four out of ten patients, impairment of endothelial function persisted at 6-month follow-up despite optimal medical therapy. Persistent impairment of endothelial function and the presence of diabetes had an independent adverse effect on clinical outcome after $31 \pm 4$ months. However, that study did not include patients with recent STEMI or other acute coronary syndromes. Nevertheless, similar to the observations of our present study, the authors found no relation between alterations in traditional risk factors in response to medical therapy and changes in endothelial function during 6 months [27].

The phenomenon of persistent impairment of endothelial function was also seen in 245 patients with chronic heart failure, in whom endothelial function was serially assessed during 6 months by flow-mediated arterial vasodilatation [28]. Despite optimal medical therapy, persistent impairment of endothelial function was seen in $53 \%$ of patients, while $47 \%$ showed an improvement. Again, there was no significant difference in clinical parameters or traditional cardiovascular risk factors between patients with persistently impaired versus improved endothelial function [28]. On the contrary, Careri et al. found that endothelial function of 60 patients with non-ST-elevation myocardial infarction (by assessment of flow-mediated arterial dilation) improved during no more than 3 months to a level that was similar to that of 40 subjects with stable coronary disease [29].

Our present study (in STEMI patients) as well as most of the previous studies (in other patient populations than STEMI patients) suggest that the continuum of endothelial dysfunction can ultimately reach a stage from whichdespite adequate or even optimal medical therapy and risk factor control-restoration is unlikely or even impossible. At that point, the total load of atheroma, genetic predisposition, or unknown other risk factors may become increasingly important for the further course of endothelial function. While we found endothelial function to decrease over time, the majority of patients did not fulfill the RH-PAT methodbased criterium of a significant endothelial dysfunction (i.e., RH-PAT index < 1.67) [9]. In addition, we can only speculate that deterioration in medication compliance or the recommencement of smoking also could have played a role.

\section{Study limitations}

Use of the femoral access route in $98 \%$ of our patients may be considered an advantage [30]. Nevertheless, our study is limited by the size of the study population. In addition, in patients with STEMI, the optimal timing of endothelial function measurement might be a matter of debate. We performed the baseline study at 1-month follow-up in order to ensure that inflammation and repair processes of the infarcted myocardium [12-14] could not disturb our measurements. Yet, we acknowledge that we cannot rule out that endothelial function may have improved during the period from the PPCI to the first RH-PAT measurement, for instance due to favorable effects of the cessation 
of smoking or the prescribed drugs, such as statins which may improve endothelial function in patients with coronary artery disease [31] and reduce cardiovascular risk in STEMI patients [32]. For that reason, the slight but statistically significant deterioration of endothelial function from baseline to 12-month follow-up could theoretically represent a relapse of the endothelial function to levels that preexisted just before the STEMI. In addition, the achieved levels of lipid lowering reflect recommendations of the period during which the study participants were treated, while current guidelines recommend an even more aggressive treatment that might improve endothelial function. Finally, we examined the impact of traditional cardiovascular risk factors on endothelial function, but we did not evaluate alcohol intake, vitamin D levels, or the levels of residual chest pain, which also might have been of interest [33-35].

\section{Conclusions}

In patients with STEMI, we observed during 12 months after PPCI a significant deterioration in endothelial function, as measured by the RH-PAT method, which could not be explained by changes in traditional cardiovascular risk profiles. These findings suggest that the continuum of endothelial dysfunction can ultimately reach a stage from which restoration is unlikely.

Funding This investigator-initiated study was done without any external funding. It was performed in a subpopulation of the RESPONSE trial, which has been funded by AstraZeneca.

\section{Compliance with ethical standards}

Conflict of interest The research department of Thoraxcentrum Twente has received research grants funded by AstraZeneca, not related to the present study. $\mathrm{CvB}$ received in the past lecture fees from AstraZeneca. RJGP is a consultant to AstraZeneca. All other authors reported to have no potential conflict of interest.

Open Access This article is distributed under the terms of the Creative Commons Attribution 4.0 International License (http://creativeco mmons.org/licenses/by/4.0/), which permits unrestricted use, distribution, and reproduction in any medium, provided you give appropriate credit to the original author(s) and the source, provide a link to the Creative Commons license, and indicate if changes were made.

\section{References}

1. Mathers CD, Boerma T, Ma Fat D (2009) Global and regional causes of death. Br Med Bull 92:7-32
2. Cannon CP, Steinberg BA, Murphy SA, Mega JL (2006) Metaanalysis of cardiovascular outcomes trial comparing intensive versus moderate statin therapy. J Am Coll Cardiol 48:438-445

3. Hasdai D, Gibbons RJ, Holmes DR Jr, Higano ST, Lerman A (1997) Coronary endothelial dysfunction in humans is associated with myocardial perfusion defects. Circulation 96:3390-3395

4. Zeiher AM, Krause T, Schächinger V, Minners J, Moser E (1995) Impaired endothelial-dependant vasodilatation of coronary resistance vessels is associated with exercise-induced ischemia. Circulation 91:2345-2352

5. Widlansky ME, Gokce N, Keaney JF Jr, Vita JA (2003) The clinical implications of endothelial dysfunction. J Am Coll Cardiol 42:1149-1160

6. Anderson TJ, Uehata A, Gerhard MD, Meredith IT, Knab S, Delagrange D, Lieberman EH, Ganz P, Creager MA, Yeung AC, Selwyn AP (1995) Close relation of endothelial function in human coronary and peripheral circulations. J Am Coll Cardiol 26:1235-1241

7. Neunteufl T, Katzenschlager R, Hassan A, Klaar U, Schwarzacher S, Glogar D, Bauer P, Weidinger F (1997) Systemic endothelial dysfunction is related to the extent and severity of coronary artery disease. Atherosclerosis 129:111-118

8. Kuvin JT, Patel AR, Sliney KA, Pandian NG, Sheffy J, Schnall RP, Karas RH, Udelson JE (2003) Assessment of peripheral vascular endothelial function with finger arterial pulse wave amplitude. Am Heart J 146:168-174

9. Bonetti PO, Pumper GM, Higano ST, Holmes DR Jr, Kuvin JT, Lerman A (2004) Non-invasive identification of patients with early coronary atherosclerosis by assessment of digital reactive hyperemia. J Am Coll Cardiol 44:2137-2141

10. Jørstad HT, von Birgelen C, Alings AM, Liem A, van Dantzig JM, Jaarsma W, Lok DJ, Kragten HJ, de Vries K, de Milliano PA, Withagen AJ, Scholte op Reimer WJ, Tijssen JG, Peters RJ (2013) Effect of a nurse-coordinated prevention programme on cardiovascular risk after an acute coronary syndrome: main results of the RESPONSE randomised trial. Heart 99:1421-1430

11. de Backer G, Ambrosioni E, Borch-Johnson K, Brontons C, Cifkova R, Dallongeville J, Ebrahim S, Faergeman O, Graham I, Mancia G, Cats VM, Orth-Gomer K, Perk J, Pyorala K, Rodicio JL, Sans S, Sansoy V, Sechtem U, Silber S, Thomson T, Wood D (2003) European guidelines on cardiovascular disease prevention in clinical practice: third joint task force of European and other societies on cardiovascular prevention disease prevention in clinical practice. Eur J Cardiovasc Prev Rehabil 10:S1-S10

12. Blum A, Schneider DJ, Sobel BE, Dauerman HL (2004) Endothelial dysfunction and inflammation after percutaneous coronary intervention. Am J Cardiol 94:1420-1423

13. Solheim S, Grogaard HK, Hoffmann P, Arnessen H, Seljeflot I (2008) Inflammatory responses after percutaneous coronary intervention in patients with acute myocardial infarction or stable angina pectoris. Scand J Clin Lab Invest 68:556-562

14. Sakabe K, Fukuda N, Wakayama K, Nada T, Shinohara H, Tamura Y (2004) Time course differences for statin-induced pleiotropic effects in hypercholesterolemic patients. Int J Cardiol 94:111-117

15. Kandhai-Ragunath JJ, Jørstad HT, de Man FH, Peters RJ, von Birgelen C (2013) Approaches for non-invasive assessment of endothelial function: focus on peripheral arterial tonometry. Neth Heart J 21:214-218

16. Kandhai-Ragunath JJ, Jørstad HT, de Wagenaar B, de Man FH, Stoel MG, van Es J, Doelman CJ, Doggen CJ, Peters RJ, von Birgelen C (2014) Assessment of the relation between initial culprit vessel patency in acute ST-elevation myocardial infarction and endothelial function. EuroIntervention 10:784-791

17. Hamburg NM, Keyes MJ, Larson MG, Vasan RS, Schnabel R, Pryde MM, Mitchell GF, Sheffy J, Vita JA, Benjamin EJ (2008) 
Cross-sectional relations of digital vascular function to cardiovascular risk factors in the Framingham heart study. Circulation 117:2467-2474

18. Targonski PV, Bonetti PO, Pumper GM, Higano ST, Holmes DR, Lerman A (2003) Coronary endothelial dysfunction is associated with an increased risk of cerebrovascular events. Circulation 107:2805-2809

19. Gokce N, Keaney JF Jr, Hunter LM, Watkins MT, Nedeljkovic ZS, Menzoian JO, Vita JA (2003) Predictive value of noninvasively determined endothelial dysfunction for long-term cardiovascular events in patients with peripheral vascular disease. J Am Coll Cardiol 41:1769-1775

20. Wang X, Guo F, Li G, Cao Y, Fu H (2009) Prognostic role of brachial reactivity in patients with ST myocardial infarction after percutaneous coronary intervention. Coron Artery Dis 20:467-472

21. Takase B, Uehata A, Akima T, Nagai T, Nishioka T, Hamabe A, Satomura K, Ohsuzu F, Kurita A (1998) Close relation between endothelium-dependent-flow-mediated dilatation in coronary and brachial artery in human. J Am Coll Cardiol 31:359A

22. Schroeder S, Enderle MD, Ossen R, Meisner C, Baumbach A, Pfohl M, Herdeg C, Oberhoff M, Haering HU, Karsch KR (1999) Noninvasive determination of endothelium-mediated vasodilatation as a screening test for coronary artery disease: pilot study to assess the predictive value in comparison with angina pectoris, exercise electrocardiography, and myocardial perfusion imaging. Am Heart J 138:731-739

23. Neunteufl T, Heher S, Katzenschlager R, Wolfl G, Kostner K, Mauer G, Weidinger F (2000) Late prognostic value of flowmediated dilatation in brachial artery of patients with chest pain. Am J Cardiol 86:207-210

24. Lev EI, Kornowski R, Vaknin-Assa H, Ben-Dor I, Brosh D, Teplitsky I, Fuchs S, Battler A, Assali A (2009) Effect of previous treatment with statins on outcome of patients with ST-segment elevation myocardial infarction treated with primary percutaneous coronary intervention. Am J Cardiol 103:165-169

25. Sposito AC, Santos SN, da Faria EC, Abdalla DS, da Silva LP, Soares AA, Japiassu AV, Quinaglia e Silva JC, Ramires JA, Coelho OR (2011) Timing and dose of statin therapy define its impact on inflammatory and endothelial responses during myocardial infarction. Arterioscler Tromb Vasc Biol 31:1240-1246

26. Brown BG, Zhao XQ, Sacco DE, Albers JJ (1993) Lipid lowering and plaque regression: new insights into the prevention of plaque disruption and clinical events in coronary disease. Circulation 87:1781-1791

27. Kitta Y, Obata JE, Nakamura T, Hirano M, Kodama Y, Fujioka D, Saito Y, Kawabata K, Sano K, Kobayashi T, Yano T, Nakamura K, Kugiyama K (2009) Persistant impairment of endothelial vasomotor function has a negative impact on outcome in patients with coronary artery disease. J Am Coll Cardiol 53:323-330

28. Takishima I, Nakamura T, Hirano M, Kitta Y, Kobayashi T, Fujioka D, Saito Y, Watanabe K, Watanabe Y, Mishina H, Obata J, Kawabata K, Tamaru S, Kugiyama K (2012) Predictive value of serial assessment of endothelial function in chronic heart failure. Int J Cardiol 158:417-422

29. Careri G, Nerla R, Di Monaco A, Russo G, Stazi A, Villano A, Sestito A, Lanza GA, Crea F (2013) Clinical correlates and prognostic value of flow mediated dilatation in patients with nonST segment elevation acute coronary syndromes. Am J Cardiol 111:51-57

30. Latsios G, Antonopoulos AS, Oikonomou E, Mourouzis K, Giannaki A, Papamikroulis A, Tsiamis E, Papaioannou S, Toutouzas K, Tousoulis D (2016) Effects of transradial coronary catheterization on systemic and local vascular endothelial function and inflammatory process. Int J Cardiol 223:109-110

31. Takayama T, Hiro T, Yoda S, Fukamachi D, Haruta H, Kogo T, Mineki T, Murata H, Oshima T, Hirayama A (2017) Effect of Aggressive lipid-lowering treatment with Rosuvastatin on vascular endoTHelium function: evaluation of vascular endothelium function (EARTH study). Heart Vessels. https://doi.org/10.1007/ s00380-017-1094-0

32. Miyachi H, Takagi A, Miyauchi K, Yamasaki M, Tanaka H, Yoshikawa M, Saji M, Suzuki M, Yamamoto T, Shimizu W, Nagao K, Takayama M (2016) Current characteristics and management of ST elevation and non-ST elevation myocardial infarction in the Tokyo metropolitan area: from the Tokyo CCU network registered cohort. Heart Vessels 31:1740-1751

33. Oda N, Kajikawa M, Maruhashi T, Iwamotot $Y$, Kishimoto $S$, Matsui S, Hidaka T, Kihara Y, Chayama K, Gotot C, Aibara Y, Nakashima A, Noma K, Tomiyama H, Takase B, Yamashina A, Higashi Y (2017) Endothelial function is impaired in relation to alcohol intake even in the case of light alcohol consumption in Asian men; Flow-mediated Dilation Japan (FMD-J) Study. Int J Cardiol 230:523-528

34. Muscogiuri G, Annweiler C, Duval G, Karras S, Tirabassi G, Salvio G, Balercia G, Kimball S, Kotsa K, Mascitelli L, Bhattoa HP, Colao A (2017) Vitamin D and cardiovascular disease: from atherosclerosis to myocardial infarction and stroke. Int J Cardiol 230:577-584

35. van Houwelingen KG, van der Heijden LC, Lam MK, Kok MM, Löwik MM, Louwerenburg JW, Linssen GC, IJzerman MJ, Doggen CJ, von Birgelen C (2016) Long-term outcome and chest pain in patients with true versus non-true bifurcation lesions treated with second-generation drug-eluting stents in the TWENTE trial. Heart Vessels 31:1731-1739 